\title{
Problems and Countermeasures of Urban Ecological Civilization Construction in China
}

\author{
Xin Yu \\ Northeastern University, Shenyang, China \\ Email: 904931348@qq.com
}

How to cite this paper: $\mathrm{Yu}, \mathrm{X}$. (2019) Problems and Countermeasures of Urban Ecological Civilization Construction in China. Low Carbon Economy, 10, 1-10. https://doi.org/10.4236/lce.2019.101001

Received: December 24, 2018

Accepted: January 20, 2019

Published: January 23, 2019

Copyright (C 2019 by author(s) and Scientific Research Publishing Inc. This work is licensed under the Creative Commons Attribution International License (CC BY 4.0).

http://creativecommons.org/licenses/by/4.0/

\section{(c) (†) Open Access}

\begin{abstract}
The construction of urban ecological civilization is an important part of the construction of a beautiful China. There are some problems in the construction of urban ecological civilization in China, such as the weakness of ecological consciousness, the dislocation of the political achievements, and the imperfect institution. The article will discuss the approaches and strategies of urban ecological civilization construction from the perspective of consciousness, economy, environment, institution, and carry out systematic optimization, in order to speed up the pace of urban ecological civilization construction, promote the harmonious coexistence between man and nature, build a beautiful China, and realize the great rejuvenation of the Chinese nation.
\end{abstract}

\section{Keywords}

City, Ecological Civilization, Ecological Economy, Ecological Environment, System

\section{Introduction}

The construction of urban ecological civilization is the embodiment and action oriented of ecological civilization, which reflects the progress of harmony between human and nature. The research on the problems and countermeasures of urban ecological civilization construction in China can further enrich and perfect the theory of ecological civilization construction. At present, our country is in an important period when the urbanization is developing rapidly. How to strengthen the construction of urban ecological civilization is the key to building a beautiful China. Only when the construction of urban ecological civilization is vigorously developed can we build a beautiful China and move towards a new era of ecological civilization. 
The article will discuss the construction of urban ecological civilization in China from the following three parts: the first part points out the main problems existing in the construction of urban ecological civilization in China. That is: the public ecological consciousness is weak, and some leading cadres have misplaced views on achievements, and the institution of urban ecological civilization construction is imperfect. The second part, in view of the above problems, puts forward the specific strategies for the construction of urban ecological civilization in China. That is to strengthen the cultivation of urban residents' ecological consciousness, promote the construction of urban ecological economy, strengthen the construction of urban ecological environment and strengthen the institution for promoting urban ecological progress. The third part is the conclusion part. It is proposed to further strengthen the construction of urban ecological civilization in China by the way of system optimization.

\section{Problems in the Construction of Urban Ecological Civilization in China}

\subsection{Lack of Public Ecological Consciousness}

Since China's reform and opening up, the economy and the society have developed rapidly, but the public's consciousness about ecological civilization is obviously backward and the ecological consciousness is weak, which restricts the development of economy and society to a certain extent.

The main manifestations are as follows: First, lack of consciousness to urban ecological civilization construction. Most citizens think that ecological civilization construction is only to control environmental pollution. What they can do is no littering, no spitting, but they have not a strong sense of participation in other practical activities. What's more, they ignored the ecological civilization is to promote the harmonious coexistence between man and nature and to improve the quality of human existence.

Second, the deviation of their own social role positioning. The public think that the main manager and executor of urban ecological civilization construction should be the government. Their own role is minimal, which further intensifies the low participation of citizens in the construction of urban ecological civilization.

\subsection{Some Leading Cadres Have Misplaced Views on Achievements}

For a long time, in order to pursue the local economic benefits, some leading cadres have formed the inertial thinking guided by GDP. "Resource consumption, environmental damages and ecological benefits have not been fully included in the evaluation system for economic and social development and the evaluation system for political performance. The specific operable and visible ecological development index system is not sound, and the assessment system is not strict enough" [1]. The wrong performance view of the government leads to the delay in dealing with the illegal behaviors that are found and received to de- 
stroy the ecological environment acts. The cases suspected to crimes are not handed over, and the administrative punishment is not in accordance with the law. In addition, as a result of the erroneous view of political achievements, some leading cadres have only done some environmental management work according to their own material and financial conditions, the propaganda and mobilization of the construction of urban ecological civilization is insufficient in breadth and depth, and the efforts of ecological civilization construction are not enough.

\subsection{The Institution of Urban Ecological Civilization Construction Is Imperfect}

The construction of urban ecological civilization should be guided by the institution. Indeed, the huge investment can immediately solve the ecological and environmental problems in a short term. However, if the institution is not developed and perfected, the effect of the urban ecological civilization construction will lose its sustainability. So the following problems exist in the construction institution of urban ecological civilization in China: firstly, lack of legal institution in individual fields. In recent years, although the legal institution for the construction of urban ecological civilization in China has been on the rise, however, there are still many areas of deficiencies and gaps. For example, the laws and regulations in the fields related to the daily life of citizens are not clear, which leads to the lack of legal basis for environmental protection work at the grass-roots level and the poor results in environmental protection work. Secondly, the supervision mechanism is not perfect. Due to the government's understanding about the importance of urban ecological civilization construction is insufficient, as well as the weak ecological consciousness of enterprises, social organizations and citizens that lead to the supervision mechanism of urban ecological civilization construction is not perfect, the feedback is not timely and the effect is not satisfactory. Finally, there is a lack of incentive mechanism. The public's participation in the construction of urban ecological civilization is positively correlated with the incentive policy. The lack of effective incentive mechanism leads to the weak public participation in the construction of urban ecological civilization, and it's further hindering the effectiveness of the supervision mechanism.

\section{Countermeasures for the Construction of Urban Ecological Civilization in China}

The lack and weakening of any element in the construction system of urban ecological civilization will affect the coordinated development of the whole system. Therefore, in the system of urban ecological civilization construction, it is necessary to coordinate the development of ecological economy, ecological consciousness, ecological institution and ecological environment, so as to make it produce systematic joint forces and promote the benign operation of urban eco- 
logical civilization construction system.

\subsection{Strengthening the Cultivation of Urban Residents' Ecological Consciousness}

The cultivation of urban residents' ecological consciousness provides the spiritual power for the construction of urban ecological civilization that is the logical development and materialization of the ecological consciousness in urban scope.

Urban residents are not only the main body of the construction urban ecological civilization, but also the object of ecological consciousness cultivation. Only when the urban residents have a higher ecological consciousness and ecological participation can really push forward the construction of urban ecological civilization. The cultivation of urban residents' ecological consciousness should pay attention to the coordination of ecological civilization education, ecological civilization propaganda and public participation.

First, strengthen ecological civilization education. It is necessary to bring ecological education into the educational system, through classroom teaching to educate young students to care for the natural environment of the city, and to cultivate their aesthetic ability to the natural landscape of the city. Let them in the green atmosphere continue to accept the infection of ecological consciousness. By perfecting the education course system and teaching methods of ecological civilization, the effectiveness of teaching can be improved, and the students will form the ecological consciousness of caring for their homes and protecting the livable environment of human beings in the process of freedom and consciousness. Secondly, strengthen the consciousness of ecological civilization propaganda. As the city is the distribution center of various information transmission and flow, and it's also a gathering area for the propaganda media, so, it is possible to make full use of various media means such as newspapers, radio, television, and the Internet to spread and educate citizens on ecological awareness, in order to promote the cultivation of the ecological consciousness of the whole people. Finally, enhance the public's participation in the construction of urban ecological civilization. When the government in formulating economic development decision-making, "the opinions and suggestions of citizens, legal persons and other organizations on environmental protection related matters or activities may be solicited by soliciting opinions, questionnaires, organizing symposiums, expert seminars, hearings, etc." [2]. In order to stimulate the public to participate in the construction of urban ecological civilization and further enhance public consciousness of ecological civilization, the decision must be made on the basis of comprehensive evaluation of relevant opinions and suggestions. In addition, the organization of ecological public welfare activities of the whole people can also stimulate the participation of the public and enable them to feel and experience the important value of ecological concepts in practice. Large-scale ecological participation and experience activities organized by the municipal government, community and other enterprises are the best and the most effective ways to spread ecological consciousness. 
Through the synergistic effects of ecological education, ecological propaganda and public participation, ecological consciousness will generally established in society, forming social customs of respecting, conforming and protecting to the nature, and providing inexhaustible spiritual impetus for the construction of urban ecological civilization.

\subsection{Promoting the Construction of Urban Ecological Economy}

Urban ecological economy construction is the booster of urban ecological civilization construction. According to the principle of ecological rationality, the construction of urban ecological economy should be developed into circular economy, knowledge economy and ecology of technological innovation, so as to guarantee the sustainable and healthy development of urban economy, and realize the unification of economic and ecological benefits.

1) Develop the circular economy. The circular economy effectively realizes the recycling of waste by the way of reduction, reuse and recycling, and fundamentally achieves the low consumption, low emission and high efficiency of economic development. It is a typical economic development mode in line with the principle of ecological rationality. The city is a densely populated and industrially populated area with a huge amount of garbage produced by production and life. The contradiction between urban economic development and urban environmental carrying capacity is sharp. The development of circular economy can deal with urban garbage through the recycling and utilization of waste. "The circular economy breaks through the traditional one-way material flow mode of resource-product-waste, and form the material circulation flow mode of resource-product-renewable resources" [3], so that the material flow in and out of the system can be recycled to the maximum.

2) Emphasis on the Development of knowledge economy. "By using intangible resources such as knowledge, information and intelligence to make scientific, efficient and reasonable use of tangible natural resources, re-integrate the whole process of economic operation, and finally achieve the goal of coordinating economic development with resources and environment" [4]. As a center of knowledge and technology, a city is a region where knowledge-intensive industries are concentrated. Taking advantage of this characteristic is an effective method to put forth effort to develop a knowledge economy that is pollution-free, low-energy consuming and high-tech in the city. The key to the development of knowledge economy is to vigorously promote the information industry characterized by digitization and networking, to develop the education, culture and research industries which are characterized by innovation to make full use of its resources and intelligence. The knowledge economy should give full play to the advantages of intellectual utilization of resources, intangible investment of assets and industrialization of knowledge utilization. To accomplish the "clean, energy saving and high efficiency" become a new motive force to stimulate economic growth, and make the development of urban economy economized and ecologi- 
cally.

3) Strengthen the ecology of technological innovation. Design, select and innovate technologies in accordance with the ecological concept so that technology becomes a means to achieve harmony between human and nature. In order to achieve the goal of resource conservation and environmental protection at the source, we should vigorously develop reduction technology and maximize production efficiency with the minimum cost of resources and energy. "We will vigorously develop alternative technologies to replace the highly polluting old energy, inefficient old technology and old products that waste resources, by developing clean new energy sources, lightweight new materials, energy-efficient new processes and new products with high scientific and technological content, improving the efficiency of resource utilization and reducing the pressure on the environment in the production process" [5]. Ecological technology innovation is the driving force of urban ecological civilization construction. It has the dual functions of pollution control and prevention. It can participate in all links of urban ecological civilization construction, so that the ultimate goal of urban ecological civilization construction can be achieved through practical material means.

Through the development of ecological economy, which is mainly based on circular economy, knowledge economy and ecological technology innovation can realize the coordination between urban ecological benefits and economic benefits. The development of ecological economy is the core of urban ecological civilization construction and the main driving force of urban ecological development.

\subsection{Strengthening the Construction of Urban Ecological Environment}

Urban ecological environment is the basis and condition existence of urban ecological civilization system. The destruction of urban ecological environment is bound to affect the flow of system material, information and energy, and eventually lead to the collapse of urban ecological civilization system. Therefore, the construction of urban ecological environment is the most important part of the construction of urban ecological civilization.

First of all, the fundamental task of urban environmental pollution is to solve the problems of urban water, air, noise and solid waste pollution. On the one hand, advanced green technology and low carbon technology should be adopted to minimize and purify waste water, exhaust gas and waste, so that the material that flow in and out of the system can be recycled to the maximum extent. On the other hand, guided by perfect policies and regulations, enterprises and individuals should abide by the basic principles of urban environmental protection to reduce urban noise, and give residents a fresh blue sky, clear water and a quiet living environment.

Secondly, rational planning of urban landscape. Urban landscape is an important part of urban space environment, which consists of natural landscape 
and artificial landscape. Urban natural landscape refers to the natural scenery and natural resources in the urban ecosystem, such as "the urban water system, mountains, beaches, special or rare plant communities, some wildlife habitats, etc." [6]. Urban artificial landscape refers to the artificial buildings in the urban ecosystem, including cultural relics, historic sites, parks, squares, etc. Urban landscape ecological planning should pay attention to the organic combination of artificial landscape and natural landscape. The urban appearance design should be determined according to the geographical environment, climate and human conditions of the city, so as to make it have ecological and human characteristics. Xi Jinping pointed out at the 2015 central urban work conference that "urban construction should take nature as the beauty, integrate good scenery of the mountain and the water into the city, to make the water system and green space inside the city form a complete ecological network with rivers, lakes, forests and arable land outside the city. We will lay emphasis on carry out ecological restoration to lucid waters and lush mountains to the cities" [7].

Finally, establish a perfect urban environment index system. It including evaluate the status of urban greening, air quality, water quality, sound environment quality, physical environmental quality of buildings, the reasonable degree of urban landscape planning. It can accurately reflect the actual situation of urban environmental management and provide the basis for urban environmental ecological planning. In order to construct the urban environmental index system, we should make efforts to adjust it according to the actual situation of the ecological construction of urban environment, so as to improve the sensitivity and accuracy of monitoring. Positive formulation of the order parameter scan can reflect the degree of synergy among the elements of urban ecological construction, through the feedback mechanism to guide the ecological construction of urban environment along the right direction.

The evaluation index system of urban environmental indicators is the intermediate link between comprehensive management of urban environmental pollution and urban landscape ecological planning. It collects and analyzes the relevant information in the process of urban ecological environment construction. Then the feedback mechanism is transmitted to other elements, so that the urban ecological environment construction subsystem can run in an orderly manner, and the uncertainty factors in the process of urban ecological environment construction can be eliminated to the maximum extent.

\subsection{Strengthening the Institution for Promoting Urban Ecological Progress}

The institution of urban ecological civilization is an effective means to guarantee and encourage the smooth progress of urban ecological civilization construction. The perfect institution of urban ecological civilization can ensure full development of the functions of all subsystems in the construction of urban ecological civilization and provide a good institutional environment for the institution construct of ecological civilization city. There are three interrelated elements in 
the institution of urban ecological civilization subsystem, that is, to establish and perfect the urban ecological legal supervision institution, the supervision and incentive mechanism, the evaluation scheme.

1) Establish and improve the legal institution for the urban ecological civilization construction. A complete legal system is the soft power for the urban ecological civilization construction and the sign of improving ecological civilization level. In addition to perfect the legal system of pollution prevention and control of water, atmosphere, noise and solid waste, and relevant laws concerning the daily life of citizens should also be established to guide the construction of urban ecological civilization with the mandatory binding force of laws. Furthermore, it is necessary to perfect the law enforcement system for the construction of urban ecological civilization, we could establish an environmental law enforcement department, namely the Environmental Supervision Bureau and the others relevant government departments. For example, the law enforcement agencies are jointly formed by the Environmental Protection Bureau, the Water Conservancy Bureau and other departments. By going deep into the environment scene, investigating and collecting evidence, imposing serious penalties on enterprises, units and individuals who destroy the urban ecological environment should be effectively stopped to do damage to the ecological environment. Furthermore, the effective implementation of various laws for the construction of urban ecological civilization should be ensured.

2) Improve the supervision and incentive mechanism for the construction of urban ecological civilization. On the one hand, in the form of legislation, social organizations, the media and the public have the right to supervise the environmental protection activities of the government and enterprises. We should establish a supervision mechanism composed of social organizations, media and the public to supervise and control urban ecological construction through media exposure, social organizations, public supervision and complaints. This requires social organizations and the public to fully definite the environmental information of enterprises, explicit the discharge of pollutants by key enterprises, supervise the disclosure of self-monitoring information of pollutant discharge by enterprises, participate in the assessment of environmental credit rating of enterprises, and actively put forward suggestions to the government for the environmental protection work. On the other hand, social organizations and the public that supervise and report environmental violations should be rewarded with material incentive to encourage them to take a more active part in the supervision. In order to encourage enterprises to actively save energy and reduce emissions, we should establish tax incentive policies for pollutant discharge, implement policies of "the more energy consumption, the more tax payment; the less pollutant discharge and the less tax payment", and give preferential policies and preferences in other aspects to encourage them to actively save energy and reduce emissions.

3) Establish and improve the evaluation system for the construction of urban ecological civilization. First, perfect the evaluation system of urban ecological 
environment. Monitoring and evaluation the basic of natural environment such as urban atmosphere, water, soil and noise to reflect the real level of urban ecological environment construction in real time and provide strong data support for urban ecological construction. Secondly, improve the urban Eco-economic evaluation system. To assessment the energy consumption per unit of GDP, waste reuse rate, proportion of high-tech industries and environmental protection investment index, and form an evaluation system for the efficiency of urban economic development which provides decision-making basis for resolving the contradiction between economic development and environmental protection. Finally, improve the social evaluation system for the construction of urban ecological civilization. Based on the natural population growth rate, life expectancy, the popularity rate of ecological consciousness, the public participation and so on, evaluation system for the urban ecological and social development situation should be formatted. Through the quantitative analysis of the development about the residents' physical and mental health and their real quality of life, scientific and reasonable reflect the effect of urban ecological civilization construction, and providing guidelines to the urban ecological civilization development direction.

The subsystem of urban ecological system construction is a networked organism composed of various elements. The elements complement and coordinate each other, thus forming a large network to ensure the smooth running of urban ecological civilization construction. It has achieved full coverage of the system and close cooperation between various systems, so as to leave no room for the damage behavior to the urban ecological civilization construction.

\section{Conclusion}

From the above analysis, we can come to the conclusion that the construction of urban ecological civilization in China is a complex system which is composed of ecological consciousness, economy, environment and institution elements. The core of the construction of urban ecological civilization is to make all elements of the system harmonious and orderly, synergistic and symbiotic, and coordinated development, so as to realize the maximization of its overall function and the efficient construction of urban ecological civilization. Implementation of the whole optimization of urban ecological civilization construction system is mainly through creative adjustment and transformation of the relationship between each subsystem, making the cooperation more harmonious and reducing the repulsion between the subsystems. It can also make the subsystems orderly in structure, logically self-consistent, complementary in function, giving full play to the synergy among the subsystems, to realize the complement of material, energy and information flow among subsystems. The whole optimization of urban ecological civilization construction system can make each subsystem evolve from complex, changeable and disordered fluctuation state to harmonious, orderly, balanced and complementary orderly fluctuation state. In order to promote the 
city as a whole system towards pleasant ecology, cultural diversity, economic prosperity, social harmony and perfect ideal state, we must make the ecological rationality as the core concept, sustainable development as the basic principles, by means of green technology innovation, to integrate urban ecological consciousness, economic, environmental and systemic construction, exert the self-organization mechanism of the construction of urban ecological civilization system. The city transition should be promoted to the ideal state that is ecological good, cultural diversity, economic prosperity, social harmony and institutional perfection.

\section{Conflicts of Interest}

The author declares no conflicts of interest regarding the publication of this paper.

\section{References}

[1] Wang, S. (2018) Problems and Countermeasures of Urban Ecological Civilization Construction System. Journal of Jilin Education College, 34, 161.

[2] Editorial Department. (2015) Measures for Public Participation in Environmental Protection. China Environment News.

[3] Qin, S.-S., et al. (2012) The Dilemma of Carrying out Green Consumption in Shenyang and Its Solution. Journal of Coastal Enterprises and Technology, No. 12, 59.

[4] Yang, R.-J. and Shu, J.-M. (2007) Construction and Planning of Ecological City. Economic Daily, Beijing.

[5] Jin, Y. (2004) Circular Economy and Science and Technology. Journal of Coastal Enterprises and Technology, No. 4, 1-6.

[6] Li, T.-S. and Shi, T.-M. (1998) On Urban Landscape Ecological Planning. Chinese Journal of Ecology, No. 5, 64.

[7] Literature Research Office of the CPC Central Committee. (2017) Excerpt from Xi Jinping's Discussion on the Construction of Socialist Ecological Civilization. Central Party Literature Press, Beijing. 